\title{
Endogenous switching costs and exclusive systems applications
}

\author{
JUSTUS HAUCAP* \\ Institute for Economic Policy, University of the Federal Armed Forces Hamburg
}

\begin{abstract}
This paper reviews Garcia Mariñoso's 2001 Journal of Industrial Economics article on endogenous switching costs and product compatibility. In that paper, Garcia Mariñoso concludes that producers of so-called product systems (which consist of hardware or platforms plus applications) can have strong incentives to achieve compatibility so that applications can be used with different hardware/platforms. This is because compatibility reduces consumer switching costs which in turn allows producers to charge higher prices for the hardware or platform initially. However, compatibility does not always need to be efficient, and there is a risk of excess compatibility. The issue is relevant for goods such as videogame systems like Sony's Play Station, but also for $3 \mathrm{G}$ mobile communication systems where users first buy mobile handsets and later purchase services from socalled content providers.
\end{abstract}

\section{Introduction}

Network industries differ in many respects from other industries. One distinctive feature are consumer switching costs. If consumers decide not to purchase from their previous supplier any longer, but to switch to a different firm instead, they usually incur some additional cost - even if the firms' products are functionally identical (see Klemperer, 1987a). These so-called switching costs may be exogenous or endogenous. Exogenous switching costs are not created by the relevant producer, but can be taken as given. Examples are the consumer's cost of gathering information about alternative suppliers or the cost of giving up a telephone number if there is no number portability (see Aoki and Small, 1999). ${ }^{1}$ In contrast, endogenous switching costs are artificially created by suppliers, for example, through contract termination fees or through customer loyalty schemes such as frequent flyer programmes.

While exogenous switching costs have received considerable attention in the economics literature (see Klemperer, 1995, for a survey), there is less literature on the strategic creation of endogenous switching costs. In a recent paper, Garcia Mariñoso

\footnotetext{
* Mailing address: Institute for Economic Policy, University of the Federal Armed Forces Hamburg, Holstenhofweg 85, D-22043 Hamburg, Germany. E-mail: justus.haucap@ unibw-hamburg.de The author thanks Heide Coenen, Jörg Gröhndahl, Manfred Holler and Tobias Langenberg for helpful comments and discussions.

${ }^{1}$ Since firms may decide to pay the switching costs or to invest into reducing consumers' switching costs, e.g. through informative advertising or implementing number portability, the height of consumers' switching costs is not truely exogeneous in equilibrium, strictly speaking. However, in contrast to artificially created switching costs the costs mentioned above are initially given, but not created.
} 
(2001) has addressed the issue in the context of product systems and the strategic choice of product compatibility.

Product systems consist of various parts or services that can only be used together even though they may be bought separately. An example are video game systems such as Nintendo's GameCube, Sony's Play Station or Microsoft's Xbox which consist of a console and system-specific game CDs or cartridges. Similarly, for mobile telecommunications services one needs a mobile handset and can later purchase mobile communications or entertainment services ("content"). Since consumers usually purchase the different parts or services sequentially in these markets, intra-brand incompatibility generates consumer switching costs. That is, consumers usually first purchase a console plus some initial games while they later buy additional games that usually will not have been developed at the time of the initial purchase. Similarly, with 3G mobile communications systems consumers may buy a mobile handset and sign a contract with one particular network operator at some point and later purchase services from various content providers. This content may be exclusive to one network or be available on all mobile networks (non-exclusive content). In the following, I will more generally refer to the console or mobile handset as the platform and to the games or other services as applications.

If the different product systems are compatible, then the applications are not exclusive to one particular platform. In contrast, with system incompatibility the respective applications are exclusive to one platform. Application exclusivity or system incompatibility creates switching costs, as consumers have to purchase a new platform if they want applications that are designed for a different platform than the one that they already possess. For example, if a consumer already owns, say, a Play Station and now wants to play another videogame, they have to buy a new videogame plus a GameCube or Xbox console if they want to switch, but they only need to buy the videogame (but not the console) if they stick with their Play Station.

In this context, Garcia Mariñoso (2001) studies whether "incompatibility can indeed be used by firms as a strategic tool to lock-in consumers and limit competition in aftermarkets". The key result is that, while the above is a possibility, product system suppliers can also have strong incentives to voluntarily make their platforms compatible and the respective applications non-exclusive if the fixed cost of achieving compatibility/non-exclusivity is sufficiently low. Furthermore, compatibility is also efficient if the fixed costs of achieving and maintaining compatibility are not prohibitively high. If these costs are sufficiently high, there can be even excess compatibility. This is because compatibility guarantees consumers access to their preferred complement without incurring switching costs, which in turn increases their willingness to pay and, thereby, the price the producer can initially charge for the platform. However, the additional producer surplus may be smaller than the social benefit of compatibility.

\section{Discussion of the model}

The paper uses a two-period duopoly model with firms competing in prices. Furthermore, and this is crucial, in the second period firms can perfectly price-discriminate between their old customers and new customers that switch from the other firm. This second period price discrimination is achieved by offering a bundle consisting of new applications and 
the platform on the one hand and only the new applications on the other hand. As only new customers are interested in buying the bundle including the platform (since the old users already have it), this mechanism can be used to price discriminate.

In the first period, platforms are sold (including some initial applications), ${ }^{2}$ while in the second period newly developed applications are sold either separately or jointly with the platform (including the old applications). It is assumed that consumers consider the platforms homogeneous goods in the first period. However, when new applications have been developed in the second period consumers learn what set of second period applications they prefer. That means the applications available in period 2 are heterogeneous goods for consumers. Regarding their preferences for the two application sets, consumers are uniformly distributed with unit density between the two firms, A and $\mathrm{B}$, on a Hotelling line of length $L$, and "transport costs" are $t=1$.

\subsection{System incompatibility (exclusive applications)}

If the two firms' applications are not compatible with each other's platforms the two firms' second-period profits are given by

$\Pi_{i}^{2}=s_{i}\left(p_{i y}-c_{y}\right) I_{i}+s_{j}\left(p_{i x}+p_{i y}-c_{x^{-}} c_{y}\right) I_{j}$

for $i, j=\{A, B\}$ with $i \neq j$ where $s_{i, j}$ stands for firm $i$ and $j$ 's respective market share in period 1 (i.e. the number of their previous customers), $p_{i x}$ for firm i's platform price and $p_{i y}$ for the price of its new application package. Similarly, $c_{x}$ and $c_{y}$ denote the respective (constant) marginal cost of producing the platform $(x)$ and the new application package $(y)$. Hence, $p_{i}=p_{i x}+p_{i y}$ is the price for the bundle "platform plus new applications" and $c=c_{x}+$ $c_{y}$ is the bundle's production cost. ${ }^{3}$ Furthermore, the number of "old" consumers who do not switch to the competitor, but remain loyal and purchase firm $i$ 's new applications is given by $I_{i}=(1 / 2)\left(p_{j x}+p_{j y}-p_{i y}+L\right)$, while the number of "new" customers who switch from the competitor and now buy the bundle of firm $i$ 's new applications plus its platform is given by $I_{j}=(1 / 2)\left(p_{j y}-p_{i x}-p_{i y}+L\right)$. Hence, profits are given by (a) the old customers that remain loyal and purchase the new applications package $\left(s_{i} I_{i}\right)$ multiplied with the profit per new applications package $\left(p_{i y}-c_{y}\right)$ plus (b) the new customers that have previously been with the competitor and now buy the bundle $\left(s_{j} I_{j}\right)$ multiplied with the profit per bundle $\left(p_{i}-c\right)$.

There are two possible second period (Nash) equilibria, depending on the cost of producing additional platforms. If the cost of producing more platforms is prohibitively high $\left(c_{x}>3 L\right)$, all consumers are perfectly locked-in and no user switches from one system to another. Firms will simply exploit their customer base in period 2. If, however, the cost of producing more platforms is relatively low $\left(c_{x}<3 L\right)$, some consumers will switch from one system to the other. The respective prices are given by $p_{i y}=L+c_{y}+1 / 3 c_{x}$ and $p_{i x}=1 / 3 c_{x}$, where the latter is the consumer's cost of buying the other platform, i.e. the

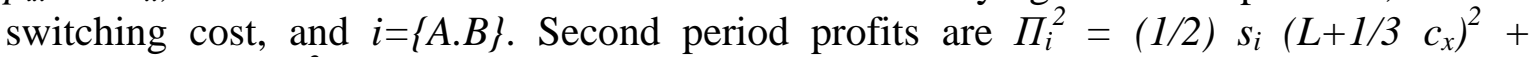
$(1 / 2) s_{j}\left(L-1 / 3 c_{x}\right)^{2}$

Given this, Garcia Mariñoso's first result is that, while switching costs are not zero, the second-period price for platforms is below their production cost. That means that firms are

\footnotetext{
${ }^{2}$ For the model it is important that the platforms sold in period 1 have some functionality so that users derive some utility. Otherwise, nobody would buy a platform in period 1.

${ }^{3}$ Note that $p_{i x}$ is an implicit price if firms only sell complete packages in period 2.
} 
subsidising consumers to switch while at the same time extracting as much surplus as possible from their captured customers. Also note that, even though the platform price is below marginal cost, this is not the outcome of some predation strategy, but the result of simple profit maximization. In contrast, firms earn non-negative profits on the bundle consisting of platform plus applications. Nevertheless, the below-cost-price for the platform has adverse welfare effects: As the private cost of switching between suppliers is given by $p_{i x}=1 / 3 c_{x}$ and, therefore, below the social cost of producing additional platforms $\left(c_{x}\right)$, there is excessive switching from an efficiency point of view.

A second result is that with endogenous switching costs, prices in the second period do not depend on the firms' first period market shares. This is in stark contrast to exogenous switching cost models where firms with large initial market shares tend to become "fat cats" that would rather exploit their customer base than attract new customers in period 2 (see, e.g., Klemperer, 1987b). This difference results from the inability to differentiate between old and new customers in exogenous switching cost models, while in Garcia Mariñoso's model firms can perfectly distinguish old from new customers and perfectly price-discriminate between the two consumer groups.

In line with other switching cost models, first-period profits are negative and exactly offset second-period profits if consumers are perfectly locked-in $\left(c_{x}>3 L\right)$, while profits are only partially competed away in the first period if some consumers do actually switch in period $2\left(c_{x}<3 L\right)$. Hence, consumers are compensated in period 1 for being locked-in (and "exploited") in period 2.

What is critical though, is Garcia Mariñoso's (implicit) assumption that there is no second-hand market for used platforms. If there was a second-hand market for platforms, firms could no longer set the prices for their platforms independently. Instead those consumers that wanted to switch to the alternative system would be willing to dump their old platform onto the market for any non-negative price. The higher the second-hand market price for used platforms, the lower are, ceteris paribus, consumers' switching costs and the more consumers are willing to switch, which in turn increases the supply of used platforms and thereby reduces their price. Unfortunately, modelling second-hand platform markets appears to be extremely difficult in this framework so that it is not intuitively obvious what kind of equilibrium (if any) may result.

\subsection{System compatibility (non-exclusive applications)}

If systems are compatible, new applications are not exclusive any longer, and there is no reason to buy a different platform in period 2. Hence, there are no switching costs in buying applications from alternative providers and the standard Hotelling equilibrium prevails with $p_{i y}=L+c_{y}$ and $\Pi_{i}^{2}=(1 / 2) L^{2}$. Since platforms are initially homogeneous goods in consumers' eyes, the standard Bertrand equilibrium results in period 1 with zero firstperiod profits $\left(\Pi_{i}{ }^{1}=0\right)$. However, note that, with incompatibility, first-period profits are even negative $\left(\Pi_{i}{ }^{l}<0\right)$ in order to compensate users for being locked-in later. Once consumers have bought the platform though, both firms' profits are higher with incompatible systems or exclusive applications than with compatibility, as long as firstperiod market shares $\left(s_{i}\right.$ and $s_{j}$ ) are roughly the same. ${ }^{4}$ Only if one firm has initially sold considerably more platforms than the other, second-period profits for the smaller firm

\footnotetext{
${ }^{4}$ In fact, firm i's second-period profits are higher with incompatibility as long as the competitor's firstperiod market share is smaller than $s_{j}^{*}=1 / 2+c_{x} / 12 L$.
} 
would be higher under compatibility (because it can also sell its new applications to the larger customer base). The larger firm, however, still has higher second-period profits with incompatibility. In summary, while firms' first-period profits are higher with compatibility, in period 2 the reverse can be true.

\subsection{Compatibility choice and welfare}

When deciding whether to offer compatible or exclusive applications, the sum of first and second period profits will be decisive for a firm's choice. As long as the cost of achieving compatibility is not prohibitively high, Garcia Mariñoso's model predicts that firms will choose compatibility, i.e. non-exclusive applications, as total profits over the two periods tend to be higher with compatibility. Moreover, compatibility should also be efficient from a welfare economic perspective. As there are no price effects (and no market size effects) in the model, incompatibility is inefficient (as long as the fixed cost of maintaining compatibility are small) because incompatibility leads to (a) unnecessary cost duplication as some consumers will buy two platforms and (b) some utility loss for those consumers who will, because of their switching cost, use the applications they prefer less in period 2.

If, on the contrary, the costs of achieving compatibility are high, then firms will decide to offer exclusive applications which is - in that case - also efficient, as the fixed cost of achieving and maintaining compatibility is avoided. Only when compatibility costs fall into some intermediate range, firms may decide to introduce compatibility even though incompatibility would be welfare superior. In consequence, the market can only err on the side of too much compatibility in Garcia Mariñoso's model while incompatibility can only be observed in cases where it is efficient. However, Garcia Mariñoso $(2001,292)$ also states that in an extension of the model firms' profits may be larger with incompatibility while compatibility would be socially optimal if applications are sufficiently differentiated ( $L$ is large) and consumers have a natural preference for using applications of the same brand again.

\section{Discussion and policy conclusions}

In summary, Garcia Mariñoso (2001) offers a model with a provocative conclusion: As long as consumers do not have a sufficiently strong preference for using applications of the same brand, the only policy concern can be excess product compatibility, but not incompatibility. This finding is in stark contrast to the traditional concern that strategic product incompatibility will be used as a monopolistic tying device in order to leverage monopoly power into related markets, as in the well known Berkey Photo v. Eastman Kodak case where Kodak was accused of designing its new camera and film in a format incompatible with rival manufacturers' products (see, e.g., Whinston, 1990). The reason for this difference is simply that in Garcia Mariñoso (2001), producers have no market power in the first period and, therefore, compete away most if not all of the profits. While product incompatibility leads to price discrimination, which even includes below-cost pricing for one part of the bundle, there is no leveraging of monopoly power or predatory intent.

Hence, Garcia Mariñoso's results call for caution regarding regulated standardization. However, there are also a number of assumptions which limit the paper's applicability for policy purposes. 
Firstly, prices do not affect welfare in the model as with unit demands there are no quantity or market expansion effects. Hence, it remains unclear how general the model's results are if demand is more elastic. It is also concerning that there does not appear to be any equilibrium if there are second-hand markets which are in fact observed in reality, e.g. for videogame systems.

Secondly, there are no real "new" customers in the market. Especially for growing markets such as mobile communications or markets with rapidly changing customers such as videogame systems, this is a rather heroic assumption. If there were truly new customers who had not purchased the system at all before, firms would no longer be able to perfectly price-discriminate by selling bundles on the one hand and applications only on the other.

Thirdly, it is assumed that firms can perfectly commit to either compatibility or incompatibility. This may be possible for some product systems. For example, if compatibility is a purely technological choice, it may be possible to simply standardize interfaces or reveal a source code which is non-reversible. However, if compatibility is mostly a contractual issue, which may be simply achieved through an agreement that an applications package or content is not exclusive, then any compatibility decision may easily be reversed so that credibility/time consistency issues arise. In this case, however, the firms may be tempted to make their applications exclusive in period 2, as secondperiod profits are higher with incompatibility. If, however, consumers are smart enough to foresee that firms' incentives will change in period 2, they will expect incompatibility right from the start which in turn reduces their willingness to pay for the platforms in period 1 so that firms' first-period profits decrease and their advantage of maintaining compatibility vanishes as well. In that case, there is little reason to expect compatibility even if it were efficient. Relatedly, it may be worth exploring how compatibility affects incentives to develop new applications altogether in this context.

Fourthly, what is briefly mentioned, but not really stressed in the paper, even though it is possibly quite relevant for public policy, is the fact that there is a conflict of interest between small and large firms if market shares become sufficiently asymmetric, as is, for example, the case in many mobile telecommunications markets. While large firms prefer incompatibility and exclusive applications, the reverse is true for small firms. Hence, we would expect large operators to sign exclusive arrangements with content providers (in order to prevent their customers from leaving and to make other customers leave their old operator), while small operators should prefer applications not to be exclusive. In fact, casual observations from negotiations between mobile operators and content providers appear to support this hypothesis.

\section{$4 \quad$ References}

Aoki, R. and J. Small (1999) "The Economics of Number Portability: Switching Costs and Two-Part Tariffs," Working paper, University of Auckland, online at: http://www.crnec.auckland.ac.nz/research/papers/Aoki_Small.pdf

Klemperer, P. (1987a) "Markets with Consumer Switching Costs," Quarterly Journal of Economics 102: 375-394. 
Klemperer, P. (1987b) "The Competitiveness of Markets with Switching Costs," RAND Journal of Economics 18: 139-150.

Klemperer, P. (1995) "Competition when Consumers have Switching Costs: An Overview with Applications to Industrial Organization, Macroeconomics, and International Trade," Review of Economic Studies 62: 515-539.

Garcia Mariñoso, B. (2001) "Technological Incompatibility, Endogenous Switching Costs and Lock-in," Journal of Industrial Economics 49: 281-298.

Whinston, M.D. (1990) “Tying, Foreclosure, and Exclusion," American Economic Review 80: 837-859. 